\title{
Transparencia y rendición de cuentas: exigencias de la Responsabilidad Social de las Cooperativas no Agropecuarias en Cuba
}

\author{
Yaneisi Bencomo Fariñas ${ }^{1}$ y Daimi Fernández Pacheco ${ }^{2}$
}

Recibido: 21 de mayo de 2018 / Aceptado: 14 de noviembre de 2018

Resumen. La vinculación entre los principios cooperativos y los valores que el cooperativismo promueve, y el compromiso inherente en el propio concepto de la Responsabilidad Social, justifican la necesidad de que las cooperativas articulen mecanismos en sus procesos de gestión para canalizar el conjunto de sus esfuerzos en favor de una mayor Responsabilidad Social. A tales fines, estos sujetos han de contar con un modelo de gestión social que implique la concertación de prácticas transparentes de rendición de cuentas que impulsen la justicia social, la equidad y el desarrollo local por medio del cumplimiento consecuente de los principios y valores de la filosofía cooperativista. De tal modo, serán necesarias políticas, planes estratégicos, iniciativas concretas, canales de comunicación, en fin, una estructura formal que apoye este proceso de gestión, dotado de mecanismos para la evaluación y el control; acciones todas encaminadas a dar respuesta a las expectativas de sus grupos de interés, así como mejorar la transparencia y la legitimidad de las cooperativas. Es objetivo del presente trabajo analizar, desde una posición crítica, las principales limitaciones jurídicas y prácticas existentes en torno al cumplimiento y control de la Responsabilidad Social Cooperativa de las Cooperativas no Agropecuarias en Cuba. En vistas a su cumplimiento, en primer lugar, se sistematizan posiciones doctrinales sobre la relación existente entre transparencia y Responsabilidad Social, dada la vinculación entre los principios inspiradores de la cultura cooperativa y la Responsabilidad Social Cooperativa, y de esta última con los niveles de divulgación de información. Se concluye con reflexiones sobre el papel que desempeña el Balance Social Cooperativo como instrumento de rendición de cuentas que exige y demanda una gestión cooperativa más transparente en el desarrollo de la misión social que, unida al despliegue de su actividad económica, debe ser cumplida por las cooperativas cubanas.

Palabras clave: Responsabilidad Social Cooperativa; Transparencia; Acceso a la información; Balance Social Cooperativo; Cooperativas no Agropecuarias.

Claves Econlit: G30; M14; P13.

\section{[en] Transparency and accountability of accounts: requirements of the social responsibility of non-agricultural cooperatives in Cuba}

\begin{abstract}
The link between cooperative principles and the values that cooperativism promotes, and the commitment inherent in the concept of Social Responsibility, justify the need for cooperatives to articulate mechanisms in their management processes to channel all their efforts in favor of greater Social Responsibility. To such ends, these subjects must have a model of social management that
\end{abstract}

1 Universidad de Pinar del Río "Hermanos Saíz Montes de Oca”, Cuba

Dirección de correo electrónico: yaneisi861024@gmail.com

2 Empresa Provincial de Servicios Legales de Pinar del Río, Cuba

Dirección de correo electrónico: daimi@epselpr.co.cu 
implies the conclusion of transparent accountability practices that promote social justice, equity and local development through the consequent compliance with the principles and values of the cooperativist philosophy. In this way, policies, strategic plans, concrete initiatives, communication channels will be necessary, in short, a formal structure that supports this management process, equipped with mechanisms for evaluation and control; actions all aimed at responding to the expectations of its stakeholders, as well as improving the transparency and legitimacy of cooperatives. The aim of this paper is to analyze, from a critical standpoint, the main legal and practical limitations regarding compliance with and control of the Cooperative Social Responsibility of Non-Agricultural Cooperatives in Cuba. In view of its fulfillment, in the first place, doctrinal positions on the relationship between transparency and Social Responsibility are systematized, given the link between the inspiring principles of the cooperative culture and the Cooperative Social Responsibility, and of the latter with the disclosure levels of information. It concludes with reflections on the role played by the Cooperative Social Balance as an instrument of accountability that demands and demands a more transparent cooperative management in the development of the social mission that, together with the deployment of its economic activity, must be fulfilled by the Cuban cooperatives.

Keywords: Cooperative Social Responsibility; Transparency; Access to information; Cooperative Social Balance; Non-Agricultural Cooperatives.

Sumario. 1. Introducción. 2. Transparencia y rendición de cuentas. Aproximaciones conceptuales. 3. Responsabilidad Social Cooperativa. Apuntes necesarios. 4. La Responsabilidad Social de las Cooperativas no Agropecuarias en Cuba. Principales limitaciones jurídicas y prácticas. 5. Conclusiones. 6. Referencias bibliográficas.

Cómo citar: Bencomo Fariñas, Y. y Fernández Pacheco, D. (2019) Transparencia y rendición de cuentas: exigencias de la Responsabilidad Social de las Cooperativas no Agropecuarias en Cuba. REVESCO. Revista de Estudios Cooperativos, Segundo Cuatrimestre, No 131, pp. 179-198. DOI: 10.5209/REVE.62813.

\section{Introducción}

En el contexto de la economía nacional cubana y su proceso de actualización a partir de la implementación de los Lineamientos de la Política Económica y Social del Partido y la Revolución ${ }^{3}$, las cooperativas, como forma de gestión no estatal, constituyen un componente más del Modelo Económico cubano de elevada contribución a la sostenibilidad del desarrollo económico y social de la nación; a partir de procesos de gestión económica y social, eficientes y eficaces.

Más allá de ser concebida como una organización con unidad técnica, económica y financiera, la cooperativa ha de ser considerada, en un sentido prioritario, como una institución social, debiendo fundamentar su gestión bajo una concepción de Responsabilidad Social, que integre de manera coherente y transparente factores económicos, productivos y sociales. De tal manera, las cooperativas han de desarrollar acciones que coadyuven a potenciar el desarrollo

3 El Partido Comunista de Cuba, con el objetivo de actualizar el modelo económico cubano y garantizar la irreversibilidad del Socialismo, el desarrollo económico del país y la elevación del nivel de vida de la población, emitió un documento denominado Lineamientos de la Política Económica y Social del Partido y la Revolución, aprobado en el VI Congreso del Partido el 18 de abril de 2011 y en el Séptimo Período Ordinario de Sesiones de la VII Legislatura de la Asamblea Nacional del Poder Popular el 1ro de agosto de 2011. A partir de dichos Lineamientos, y amparadas en las correspondientes disposiciones jurídicas, se han adoptado medidas, como el fomento del trabajo por cuenta propia, la creación de Cooperativas No Agropecuarias y la promulgación de una nueva Ley Tributaria. 
local del entorno donde insertan su gestión, toda vez que, tal y como afirmara Mugarra, hablar de cooperativas es hablar de organizaciones de intereses colectivos, donde las personas se unen para enfrentar sus problemas y buscar soluciones conjuntas, son entidades que buscan cumplir con un fin social siendo el aspecto económico un medio de gestión y no la finalidad última de su labor (Mugarra, 1999).

Las cooperativas son responsables socialmente por contribuir al bienestar de sus miembros y de las comunidades locales donde residen, por ser solidarias y democráticas, por dar prioridad a las personas sobre el capital, por sus políticas de participación igualitaria, o por su trabajo con colectivos especialmente desfavorecidos, entre otras cuestiones. Son igualmente responsables porque trabajan en favor de todos sus grupos de interés, siendo el socio pieza angular por sus diferentes roles en la actividad cooperativa. Lo son también ambientalmente, por su defensa del entorno natural de las zonas en las que se ubican y por el mantenimiento de la cultura y las tradiciones.

La Responsabilidad Social Cooperativa (RSC) se erige así en un compromiso obligatorio y consciente que tiene la cooperativa de contribuir con el desarrollo y el mejoramiento de la calidad y nivel de vida de sus socios, empleados, sus familias, la comunidad y la sociedad en general. En tal sentido, ha de ser de interés para los socios no solo las ganancias financieras y productivas que se han generado, sino también les deben preocupar si se originaron gastos por concepto de servicios sociales, qué beneficios sociales obtuvieron, si se brindó capacitación y educación cooperativa; el apoyo que se dio a la comunidad en la que se asientan, entre otros elementos.

En este orden resulta un imperativo disponer de herramientas concretas que permitan medir o constatar la incidencia social de las cooperativas, a fin de evaluar su impacto social, lo que necesariamente ha de realizarse en un entorno de transparencia y rendición de cuentas.

En Cuba, aún cuando las cooperativas han venido desarrollando acciones socialmente responsables, existen limitaciones en cuanto a la transparencia de la gestión cooperativa en este ámbito, cuyo análisis constituye el objetivo del presente estudio. Para ello se comenzará sistematizando los criterios teóricos que se han esgrimido en la doctrina en torno a los términos transparencia y rendición de cuentas, como componentes estos intrínsecamente vinculados a la RSC. Seguidamente serán examinadas las limitaciones que en este sentido presentan hoy las cooperativas, en particular las no agropecuarias, tomando como base además las particularidades del Balance Social Cooperativo como instrumento que permite la rendición de cuentas. Finalmente, incorporamos las necesarias Conclusiones a las que hemos arribado, siendo enlistados, en los acápites propios de la Bibliografía y la Legislación, los materiales bibliográficos y normativos consultados a los efectos del presente trabajo.

\section{Transparencia y rendición de cuentas. Aproximaciones conceptuales}

La transparencia es uno de los términos más utilizados actualmente, tanto en el ámbito político-público, como en el privado. Se ha tratado como un concepto 
abstracto sobre la apertura de normas, de comportamientos, y de a quienes éstas se aplican (ciudadanos, gobiernos, organizaciones). Responde a diferentes necesidades de difundir o compartir información, ya sean procesos, documentos, datos, acciones, decisiones, proyectos, etc. La transparencia significa incluso el asegurarse que los derechos de los ciudadanos sean respetados y que puedan participar en las decisiones que afectan sus vidas y sus intereses.

Aplicada al entorno organizacional, la transparencia significa que la empresa tiene la disposición de informar sobre su situación actual, de qué decisiones se toman y por quiénes son tomadas (Alonso, 2009). Tal información, para Villanueva, implica un manejo bajo estándares éticos, de tal forma que los criterios que se siguen, cuando se toma una decisión, puedan presentarse con claridad a las personas que tengan derecho a conocerlos (Villanueva, 2011). La transparencia implica ante todo la actitud y disponibilidad de informar (Marcuello, C., Bellostas, 2007), así como la garantía de acceso, apertura y visibilidad de la información que permita prácticas de certidumbre entre las organizaciones y los entes internos y externos que se relacionan con éstas (Uvalle, 2007). Tales procesos en ocasiones son certificados y evaluados por entidades externas, y muestran evidencia de la forma de operar de una empresa (Chávez, Patraca, 2011).

Según Heise, las organizaciones transparentes ponen a disposición del colectivo toda la información que es legalmente publicable, tanto la información positiva como la negativa (Heise, 1985). A su vez, manifiesta Gower que la transparencia informativa es el esfuerzo que realizan las instituciones para que sus actos y decisiones sean demostrables y entendibles. Al margen de la información que se dé, es importante la percepción que tiene el receptor. Según este autor, los receptores tienen que creer y sentir que la organización es transparente (Gower, 2006). Por todo ello, es necesario medir la percepción que tienen los receptores acerca de cómo se comparte dicha información; tienen que vivir la transparencia de la organización.

Por su parte, Coterrel afirma que la transparencia requiere un proceso, al que él denomina proceso de transparencia. Primero, se debe conocer la información que requiere el receptor. Por lo tanto, antes de emitirla, se deben tomar como punto de partida las necesidades del colectivo receptor. Como consecuencia y según el autor, la transparencia no es únicamente la accesibilidad de la información, sino algo más amplio; es la posibilidad de participar activamente en la creación, la distribución y obtención de la información (Coterrel, 2000). Es decir, ser parte activa en todo el proceso. La participación activa de los interesados es un elemento indispensable y primordial en el proceso de transparencia.

De tal modo, la transparencia está relacionada con la credibilidad, la confianza, la Responsabilidad Social, la ética, y todo ello, estrechamente relacionado con una mayor o menor participación del colectivo. Rawlins relaciona la transparencia con la confianza; cuanto más transparente y abierta es una organización, más confianza e implicación obtendrá por parte de los empleados, clientes y proveedores. Pero para que la transparencia sea efectiva, hay que medirla. En tal sentido nos propone este autor que para que la transparencia sea eficaz, es necesario medirla y siempre, desde la perspectiva de los grupos de interés; en nuestro caso, se trata de medir la percepción del colectivo con respecto al esfuerzo que hace la cooperativa para ser transparente. Así, la transparencia se traduce en poner a disposición del colectivo 
toda la información que pueda ser liberada; tanto la información de carácter positivo como la de carácter negativo. La información debe ser concreta, adecuada, equilibrada y limpia y deberá mejorar la capacidad de razonamiento del público; y esa información ayudará a comprender las prácticas, políticas y actuaciones de la organización responsable (Rawlins, 2009).

Ahora bien, estrechamente vinculado a la transparencia se encuentra la rendición de cuentas (Arredondo-Trapero y Vázquez-Parra, 2014; Arellano y Lepore, 2009; Sandoval, 2006; Ballvé y Debeljuh, 2006), entendida esta como una parte de la transparencia que supone la presentación de informes públicos referentes a impactos, procesos, estructuras de gobierno, fuentes de financiación (Andrade Y Yedra, 2007) y flujo de recursos (Pzá, 1997). Es ante todo un acto de responsabilidad, en donde la entidad evalúa, comunica sus logros, sus fallos, y sus planes de mejora, influyendo inevitablemente en la percepción que se tiene sobre su competitividad, innovación y productividad (Medina et al, 2011; Bravo et al, 2011).

Según Ochoa y Montes de Oca, la transparencia y la rendición de cuentas son nociones aliadas, pero que no deben confundirse. La transparencia no implica un acto de rendir cuentas a un destinatario específico, sino simplemente la de colocar la información de sus decisiones y acciones en "vitrina pública". Por otro lado, la rendición de cuentas sí denota dicha obligación, exigiendo a los gerentes o gobernantes el que informe y expongan dicha información (Ochoa y Montes de Oca, 2004), rendición de cuenta que deberá ser responsable, que no es otra cosa que la voluntad y responsabilidad para dar una explicación pertinente y concreta a la persona implicada en el asunto correspondiente (Coterrel, 2000).

Resulta fundamental pues, para la transparencia, que las organizaciones y sus gerentes estén obligados a rendir cuentas sobre sus actos, pues tanto el resto de los agentes internos, como externos a la empresa tienen derecho de conocer el por qué se están tomando las decisiones o las acciones que se realizan (Murayama, 2007).

Ciertamente la rendición de cuentas es otro elemento indispensable para que tenga lugar la transparencia. Cuando una organización pierde la confianza y credibilidad, la vía más eficaz para restablecer la confianza perdida es actuar con transparencia. Las organizaciones transparentes realizan una rendición de cuentas responsable, no solo porque aportan al colectivo información significativa y comprensible, sino también porque ponen a disposición del colectivo dicha información para que sea evaluada por parte de los grupos de interés con el fin de mejorar la gestión.

\section{Responsabilidad Social Cooperativa. Apuntes necesarios}

En los últimos años se ha prestado especial atención, tanto en el ámbito académico como empresarial, a la concepción y práctica de la RSC.

Desde sus inicios, las cooperativas han tenido en cuenta que sus acciones benefician a la gran mayoría de sus socios, incluidos los trabajadores, la comunidad y el entorno en el que operan (ACI-Américas, 2010). Se deduce por tanto que la Responsabilidad Social está en la esencia del cooperativismo y que por este motivo las cooperativas pueden actuar sin la mirada juiciosa del entorno porque han nacido 
de las mismas comunidades o son parte de ellas y no practican una forma particular de Responsabilidad Social, sino que son por y en sí mismas sociedades socialmente responsables (ACI-Américas, 2010).

El concepto Responsabilidad Social es inherente a la economía social y, más concretamente, a las cooperativas, es decir, las cooperativas y la Responsabilidad Social han bebido de las mismas fuentes y presentan muchos elementos comunes (Carrasco, 2005). En opinión de Tous y Ciruela (2005) las cooperativas son por naturaleza socialmente responsables, afirmación apoyada años más tarde por Arcas y Briones (2009) quienes señalan que la gran similitud, e incluso coincidencia, entre los valores y principios inspiradores del cooperativismo y de la Responsabilidad Social hace que sean por naturaleza socialmente responsables, y que se encuentren bien posicionadas para poner en valor esta característica diferencial. Las cooperativas son un claro ejemplo de cómo la racionalidad económica y el progreso social son compatibles con la solidaridad y la Responsabilidad Social.

Concebida como un principio cooperativo por la Alianza Cooperativa Internacional, la RSC se deriva de la propia esencia de las cooperativas, cuyos fines se amplían a cuestiones de tipo social y cultural, superando los motivos puramente económicos, de ahí que se erija en nota esencial de la identidad cooperativa (Rodríguez, 2017; Server, R. y Capó, 2009). Es el entramado de principios y valores cooperativos el que conforma o aspira a conformar la identidad cooperativa, es decir la aceptación y vinculación de los socios dentro de su realidad social, a la vez que el establecimiento y posterior reforzamiento de una sólida cultura organizacional, como factor que cohesiona y justifica la RSC.

Una definición de Responsabilidad Social que se plantea desde el ámbito cooperativo es la visión de Bastidas-Delgado, cuando se refiere a que la Responsabilidad Social de las cooperativas forma parte consustancial de la misión de la organización, pues ellas son constituidas para satisfacer las necesidades de sus asociados a través de la actividad asignada y no necesariamente a través de aumento de capital, lo que se traduce en aprovechar al máximo los siempre limitados recursos de las cooperativas, para obtener el máximo de satisfacción en lo social (Bastidas-Delgado, 2004).

Castro (2006) afirma que las sociedades cooperativas surgen desde su compromiso con el entorno, con las personas, y su desarrollo se apoya precisamente en la realización de ese compromiso, convirtiéndola en modelo de Responsabilidad Social. Como se puede observar, se trata de unas sociedades que no sólo se gestionan y controlan de forma democrática y conjunta, sino que sus fines se amplían a cuestiones de tipo social y cultural.

Como ponen de manifiesto Server y Capó (2011) la misión social de las cooperativas es la de ofrecer un servicio tanto a sus miembros como a la comunidad a la que pertenecen. Esta doble concepción económico-social introduce las diferencias más importantes entre cooperativas y no cooperativas, por cuanto será función esencial de las primeras el cumplimiento de las necesidades y aspiraciones económicas, sociales y culturales de sus socios, cuestión que sólo resulta voluntariamente asumible para otro tipo de organizaciones, como es el caso de las sociedades capitalistas. Para las cooperativas no se trata sólo de hacer economía eficaz con una mayor dosis de sensibilidad social, sino que es, en su 
esencia, pensar y hacer economía de otra manera. Consiste en mostrar que es posible ser competitivos poniendo a la persona y al colectivo en un primer plano.

De tal modo, tal y como asevera Alfonso, la RSC alude al compromiso obligatorio y consciente que tiene la cooperativa de contribuir con el desarrollo y el mejoramiento de la calidad y nivel de vida de sus asociados, empleados, sus familias, la comunidad y la sociedad, sobre la base de procesos económicos eficientes y eficaces; derivándose dos campos de acción, el interno: relacionado con asociados, empleados y familia y el externo: vinculada con los sectores con los cuales se relaciona: comunidad, clientes, consumidores, proveedores, sociedad, Estado, etc. (Alfonso et al 2009).

Tal concepción implica concebir a la cooperativa como una organización social que debe enfocar también sus recursos a las actividades que ayuden a lograr sus fines. En tal sentido, ha de ser de interés para los socios no solo las ganancias financieras y productivas que se han generado en la cooperativa, conocer si la cooperativa tuvo o no excedentes, sino también les deben preocupar si se originaron gastos por concepto de servicios sociales, qué beneficios sociales obtuvieron los socios y sus familias, si se brindaron suficiente capacitación y educación cooperativa; el apoyo que se dio a la comunidad en la que se asientan, entre otros elementos.

Se debe tener presente que las cooperativas trabajan para el desarrollo sostenible de la comunidad por medio de políticas aceptadas por sus asociados. Si bien las cooperativas están establecidas en primera instancia para el beneficio de sus miembros, no pueden olvidar que éstos viven en espacios geográficos específicos y en comunidades definidas y que la cooperativa como tal, está íntimamente ligada a su comunidad. Esta relación es de tal naturaleza que la cooperativa por su propia acción influye en la comunidad y ésta determina muchas veces la vida misma de la cooperativa. El desarrollo de la comunidad en lo económico, lo social y lo cultural es definitivo para hacer de la cooperativa un instrumento eficiente y adecuadamente manejado. Por eso los asociados deben orientar recursos y esfuerzos para contribuir y colaborar en las acciones y programas tendentes al mejoramiento de las infraestructuras y al desarrollo de la educación, la recreación y la salud en sus respectivas comunidades. En fin, el éxito económico que logre la cooperativa debe ser acompañado con beneficios sociales, para así poder dar cumplimiento a la Responsabilidad Social Directa.

La Responsabilidad Social Directa presupone entonces el compromiso de los directivos y trabajadores con la satisfacción de las necesidades y expectativas de su recurso humano y la comunidad en que se inserta, a partir de una gestión propia y de sus propios recursos, mediante el vínculo estable y sistemático con las organizaciones políticas, de masas y sociales de su ámbito interno y de su entorno inmediato (Alfonso, 2008).

El propio autor enfatiza, acertadamente, que esta Responsabilidad Social Directa es consustancial a la cooperativa, para cuya materialización requiere del compromiso consciente; la participación real; una formación ética e ideológica basada en los valores que la identifican; así como utilidades que sustenten financieramente los diferentes proyectos sociales que desarrolla la entidad; y el reconocimiento y apoyo estatal a la acción social directa que deberá manifestarse, 
entre otros factores, en la adopción de instrumentos legales que despojen el carácter voluntario u opcional de la gestión social cooperativa.

Son principalmente tales consideraciones las que sustentan la necesidad de que las cooperativas se conviertan hoy en verdaderos gestores sociales. A tales fines, estos sujetos han de contar con un modelo de gestión social transparente en el que se comprometan a contribuir con el desarrollo y mejoramiento de la calidad de vida de los asociados, de sus familias y la comunidad. En vistas a ello, las cooperativas, en primer lugar, han de realizar un diagnóstico inicial de la situación social, lo que a la par le permitirá tener claro sus Indicadores Sociales. Asimismo, han de determinar las necesidades sociales y expectativas a enfrentar -según significado social, grado de compromiso y disponibilidad de recursos-, elaborar programas sociales, determinando las funciones y tareas que correspondan al personal implicado. Por último, se ha de analizar el desempeño social de la cooperativa, a través de la rendición de cuentas que permita la valoración del impacto generado por las acciones sociales ejecutadas, lo que se plasmará en un informe de alcance público y deberá ser aprobado en la Asamblea General.

En este orden, las cooperativas deberán diseñar e implementar herramientas y técnicas que garanticen el cumplimiento efectivo de sus objetivos económicos y sociales. $Y$ es que la gestión en estas entidades ha estado encaminada, principalmente, a la consecución de metas y programas que responden al interés económico financiero en su desarrollo, relegando su fin social a procesos espontáneos, que emanan de la voluntad de sus directivos y no forman parte o se integran a la gestión socioeconómica de las cooperativas. Así, unido al balance económico que se realiza en las cooperativas -y en el que muchas veces se deja fuera el análisis de sus aspectos sociales-, se requiere la realización, con carácter obligatorio, de un Balance Social Cooperativo, instrumento de gestión socioeconómica que en esencia permite rendir cuentas a los miembros y a la comunidad sobre el impacto social de sus actividades, y a cuyo estudio dedicaremos el siguiente apartado.

\subsection{El Balance Social Cooperativo como instrumento de transparencia de la gestión cooperativa}

En la mayoría de las cooperativas, la principal actividad para informar a los asociados en las asambleas es la preparación del denominado balance económico. A través de este se informa sobre el dinero gastado, cuentas, cantidades, deudas, así como los ingresos y gastos, con el objetivo de saber si la cooperativa tuvo o no excedentes en el año. Sin embargo, el análisis de este documento se limita en la práctica al análisis de la situación económica, financiera y patrimonial de la cooperativa, resultando difícil conocer si lo que se gastó realmente sirvió para mejorar la calidad de vida de los asociados y la comunidad. Tal situación ha generado una visión incompleta y carente de transparencia en la gestión cooperativa, toda vez que los asociados solo van a tener acceso a la información referida a los estados contables de la cooperativa, en los que muchas veces se incluyen sólo los aspectos positivos de la gestión, ofreciendo así una mejor imagen. Conjuntamente, con frecuencia, la información no está cuantificada, lo que impide realizar un análisis comparativo sobre bases rigurosas y homogéneas; además del 
hecho de que, al realizarse un análisis estrictamente económico, olvidamos que la actividad cooperativa involucra también aspectos sociales que son medibles y sobre los cuales ha de rendirse cuentas de forma transparente y responsable.

Es así que, durante los últimos tiempos, se ha enfatizado en la necesidad de que la cooperativa cuente con herramientas e instrumentos que permitan evaluar el nivel de cumplimiento de las actividades que desarrolla para el cumplimiento de su misión social, en un período dado y que deberá ser auditable ${ }^{4}$. De esta manera, a través de un documento de alcance público denominado Balance Social Cooperativo (BSC), se evaluará interna y externamente el cumplimiento de la RSC, mediante el uso de indicadores sociales, lo que coadyuvará al logro de una evaluación integral de los procesos (Rodríguez, 2013).

Durante la XVII Conferencia Regional de ACI AMERICA celebrado en 2010 en la ciudad de Buenos Aires, el investigador San Bartolomé planteó que el BSC es una herramienta de la gestión socioeconómica que les facilita a las cooperativas medirse y rendir cuentas a los asociados especialmente y a todos los demás grupos de interés que están impactados por su accionar en relación con el cumplimiento de su propia esencia o identidad, es decir, desde los valores y los principios cooperativos (San Bartolomé, 2010).

El BSC, al decir de Mugarra, contiene todos aquellos beneficios adicionales a los meramente económicos que las cooperativas transfieren a sus grupos de influencia: los asociados, los empleados y la comunidad en su conjunto. Gracias a este instrumento las cooperativas contarán con un medio adecuado para medir el grado de acercamiento o alejamiento que tengan con respecto al cumplimiento de su misión como organización cooperativa, a la luz de sus principios y valores cooperativos (Mugarra, 2001).

De acuerdo a lo establecido a priori, y en opinión de Góngora y otros autores, se puede sintetizar la esencia del BSC en cuatro elementos fundamentales, quienes lo conciben como: un instrumento de medición del impacto social de la cooperativa en su comunidad; una ponderación que establece un balance, entre los beneficios sociales y el éxito en los negocios; una herramienta estratégica de evaluación sistemática del cumplimiento de los principios del cooperativismo; y una herramienta comunicacional (Góngora et al., 2017).

Con este fundamento el BSC aparece como una herramienta de la gestión socioeconómica que les facilita a las cooperativas medirse y rendir cuentas a los/as asociados/as y a todos los demás grupos de interés que están impactados por su accionar, así como del cumplimiento de sus valores y principios, y del impacto social de la organización en su comunidad. Permite retroalimentar la toma de decisiones y la asignación de recursos en el proceso de planeación, de acuerdo con la misión de la organización. A través de él se puede medir y analizar la eficacia de los programas que desarrolla la entidad y es posible comparar los alcances de la cooperativa con respecto a las metas de desempeño definidas y aceptadas previamente.

4 En efecto, contabilizar el desempeño no financiero de las entidades ha sido una reclamación exponencial de la sociedad en las últimas décadas por lo que variadas han sido las formas y modelos adoptados, desde las memorias de sostenibilidad, los indicadores del Global Reporting Iniciative (GRI), la contabilidad de triple raya final (TB1), el método de «tarjeta de puntuación del balance», por solo citar algunos. 
La elaboración periódica y sistemática del BSC posibilita ofrecer información homogénea y sistematizada de las acciones sociales llevadas a cabo por las cooperativas, al poner de manifiesto la situación social de la organización en un momento determinado y la evolución operada a través del tiempo. También es importante para detectar las debilidades y fortalezas permitiendo corregir los errores que pueden llevar a estas organizaciones al fracaso, si estos no son advertidos a su debido tiempo. Sirve para promover la interacción entre los miembros de la empresa, con relación a otras instituciones, a la par de facilitar la vinculación y comparación con otras cooperativas (Ressel y Coppini, 2012).

Adicional a lo anterior, el BSC deberá reflejar el grado y el cumplimiento de la Responsabilidad Social de la organización frente a la sociedad, y tendrá carácter obligatorio la información social en él contenida. Ello permitirá a la cooperativa dar a conocer sus objetivos éticos y sociales; reforzar la lealtad y el compromiso para con los vinculados a ella; facilitar sus procesos decisionales y mejorar el conjunto de su actividad económica y social; mostrar las bondades del cooperativismo para facilitar a los entes gubernamentales de supervisión y control, los elementos suficientes para certificar las buenas prácticas cooperativa; así como añadir valor social a sus operaciones económicas.

En fin, el BSC permite a la cooperativa estar al tanto de sí misma y sobre todo reconocer su participación como actor fundamental de la economía. Le posibilita afianzar su identidad a través del cumplimiento de sus valores y principios, así como reafirmar la confianza y credibilidad de sus socios y demás grupos de interés. Además, fortalece y destaca la imagen de su desempeño, de las distintas actividades relacionadas con el objeto social de la empresa, la cual debe ser el reflejo de la realidad de su práctica y acción social constante. El BSC viene a llenar así un espacio como un instrumento de medición y evaluación de la gestión de la Responsabilidad Social Cooperativa, lo que conduce a fortalecer no solo el sentido de pertenencia en estas entidades, sino también a ganar en transparencia durante el ejercicio de rendición de cuentas al informar a los socios sobre aspectos de la gestión cooperativa que los informes contables y financieros no permiten reflejar. Sin lugar a dudas, constituye una herramienta que legitima el control popular sobre la gestión socioeconómica de la cooperativa, al referirse más a la calidad y el destino de los gastos, que a las cantidades gastadas.

\section{La Responsabilidad Social de las Cooperativas no Agropecuarias en Cuba. Principales limitaciones jurídicas y prácticas}

En Cuba, desde el año 2012, se ha llevado a cabo un proceso de actualización del modelo económico, pretendiendo con ello establecer y desarrollar nuevas formas de expresión y existencia para la propiedad socialista, una mayor descentralización administrativa, y la asignación de un papel diferente a los nuevos y viejos actores sociales en el plano económico. En este contexto se reconocen y promueven, además de la empresa estatal socialista, otras formas de gestión, dentro de las que se encuentran las Cooperativas No Agropecuarias (CNA).

Estas noveles cooperativas fueron creadas como modelo de gestión en la economía cubana, en aras de combinar eficiencia económica con racionalidad y 
Responsabilidad Social. Su principal fin radica en brindar servicios a sus miembros y al entorno donde se desenvuelven, tratando así de satisfacer sus necesidades, de ahí que sean concebidas legalmente como organizaciones con fines económicos y sociales, que se constituye voluntariamente sobre la base del aporte de bienes y derechos y se sustenta en el trabajo de sus socios, cuyo objetivo general es la producción de bienes y la prestación de servicios mediante la gestión colectiva, para la satisfacción del interés social y el de los $\operatorname{socios}^{5}$.

Ahora bien, cuando nos detenemos a analizar el soporte legal de este principio en nuestro país, lo primero que nos salta a la vista es que fue concebido de forma restrictiva desde los propios Lineamientos de la Política Económica y Social del Partido, cuando en sus numerales 52 y $99^{6}$ se enfocaba su cumplimiento exclusivamente a las obligaciones tributarias, contemplándose de este modo únicamente a la Responsabilidad Social de un modo indirecto ${ }^{7}$.

A las CNA su misión social directa les viene por mandato del artículo 4 del Decreto Ley No. 305/12 $2^{8}$, que refrenda la Responsabilidad Social entre los principios que las impulsan, a lo interno con los socios, empleados y familia, y a lo externo con los clientes, proveedores, gobiernos locales y comunidades. Sin embargo, en el texto constitucional, no se reconoce la autonomía cooperativa, como tampoco la exigencia de la RSC, de ahí que sea este Decreto-Ley el que la contemple con una regulación muy parca cuando establece que los planes de las cooperativas tienen como objetivo contribuir al desarrollo económico y social sostenible de la nación, proteger el medio ambiente, desarrollar sus actividades sin ánimo especulativo y garantizar el cumplimiento disciplinado de las obligaciones fiscales y otras. Trabajan por fomentar la cultura cooperativista y por las satisfacciones de las necesidades materiales, de capacitación, sociales, culturales, morales y espirituales de sus socios y familiares.

En ningún otro momento del DL 305/12 se le presta atención a la RSC, no existiendo disposiciones jurídicas que impongan la obligación de planificar, controlar, registrar, medir, evaluar e informar acerca del grado de cumplimiento de este principio cooperativo en nuestras CNA, de ahí que tampoco se regule la exigencia de rendir cuentas de su impacto social a través de la realización del BSC, aun cuando es esta una exigencia legal contemplada en la Ley Marco para las

5 Cfr. Art. 2 del Decreto-Ley No. 305/2012 "De las cooperativas no agropecuarias”, Gaceta Oficial No. 053 Extraordinaria de 11 de diciembre de 2012.

6 Lineamiento 52: Fomentar la cultura tributaria y la responsabilidad social de la población, entidades y formas de gestión no estatales del país, en el cumplimiento cabal de las obligaciones tributarias, para desarrollar el valor cívico de contribución al sostenimiento de los gastos sociales y altos niveles de disciplina fiscal.

Lineamiento 99. Continuar desarrollando el marco jurídico y regulatorio que propicie la introducción sistemática y acelerada de los resultados de la ciencia, la innovación y la tecnología en los procesos productivos y de servicios, y el cumplimiento de las normas de responsabilidad social y medioambiental establecidas.

7 La Responsabilidad Social Indirecta se materializa por la cooperativa a través del cumplimiento de sus compromisos y aportes al Estado, enfocada fundamentalmente al cumplimiento de obligaciones tributarias. En el caso de Cuba, las cooperativas, según la Ley No. 113 de 23 de julio de 2012 del Sistema Tributario, están sujetas al pago de los tributos que les corresponda, y en específico, por el ejercicio de la actividad económica, se obligan a pagar los impuestos sobre Utilidades, sobre las Ventas, sobre los Servicios y por la Utilización de la Fuerza de Trabajo, con las adecuaciones previstas en los siguientes apartados, así como la Contribución Territorial para el Desarrollo Local.

8 En lo adelante DL 305/12. 
cooperativas de América Latina ${ }^{9}$ y que ha sido acogida en varios ordenamientos jurídicos internos ${ }^{10}$.

Por su parte, los Estatutos Sociales de las noveles cooperativas, aunque no se pueden considerar normas de Derecho Sustantivo, pero sí como normas que reflejan la voluntad de estos sujetos económicos, tampoco recogen en su articulado políticas o modelos de gestión referentes a la RSC, solo tienen previsto destinar un porcentaje de las utilidades a formar fondos para actividades socio-culturales, pero que no llega a materializarse en acciones concretas con impacto social.

En este sentido, cuando analizamos la normativa vigente, podemos percatarnos de que aún cuando se reconozca legamente la RSC como principio que orienta y organiza el funcionamiento de las CNA, en la práctica se continúa entendiendo a la cooperativa esencialmente como un actor económico, al que se le da seguimiento económicamente, minimizándose la evaluación de lo que socialmente puede y debe aportar a la comunidad.

Así, vemos cómo el propio DL 305/12 establece con carácter obligatorio la realización de un Balance General o Estado de Situación para evaluar el estado económico-financiero de la cooperativa ${ }^{11}$, sin que nada refiera en torno al instrumento a emplear para valorar cuantitativa y cualitativamente el impacto de la gestión social cooperativa a lo interno, con los socios, y a lo externo con las comunidades, los clientes, las instituciones del Estado y la sociedad en general.

Además, debemos tener presente que el reparto de los beneficios parte de la autonomía de la voluntad de los socios, plasmado en sus estatutos, pero en función del compromiso social de estas entidades, debe incorporarse a la contabilidad como parte de la sistemática del proceso. En otras palabras, la contabilidad debe contribuir a informar sobre la forma en que se ha generado el valor agregado y la forma en que se ha distribuido, poniendo énfasis en el aspecto social. Y es la verificación de la información social contenida en la contabilidad realizada por un profesional externo lo que la hace confiable, en base al principio de transparencia de la contabilidad, de ahí la importancia de la auditoría en este aspecto. Esta necesidad surge, como ya apuntábamos, por la confluencia de dos pilares fundamentales: de una parte, la existencia de instrumentos de gestión económica, que en muchos casos presentan análisis limitados y alejados de la naturaleza de la

9 La Ley Marco para las cooperativas de América Latina, que funge como marco referencial para las legislaciones nacionales de la región, dispone en el artículo 48 sobre Memoria y estados contables: «A la fecha de cierre del ejercicio el consejo de administración redactará una memoria sobre la gestión realizada la cual, juntamente con los estados contables y un balance que demuestre el desempeño de la cooperativa en el campo social, será sometida a la asamblea con informes de la junta de vigilancia y del auditor»; evidenciando con ello la importancia de rendir información social de conformidad con la naturaleza económica y social de la cooperativa. Ley Marco para las cooperativas de América Latina/ Alianza Cooperativa Internacional para las Américas. - 1a ed.- San José, Costa Rica: Alianza Cooperativa Internacional para las Américas, 2009.

10 A modo de ejemplos se pueden citar los siguientes: En Paraguay existe la Resolución No. 4109/2009, sobre el BSC, emitida por el Instituto Nacional de Cooperativismo (INCOOP) que obliga a las cooperativas a la presentación del balance social. De igual modo, en Ecuador, la imposición del balance social con carácter obligatorio como herramienta de evaluación del grado de cumplimiento de los principios y los objetivos sociales que informan las cooperativas tiene lugar mediante la Ley de Economía Popular y Solidaria del sistema financiero, de 2011; al respecto recalca en el fin del balance social para la preservación de la identidad cooperativa. Para aquellas entidades que no entreguen el reporte de balance social se prevén sanciones de carácter administrativo como la multa pecuniaria y la suspensión temporal o definitiva del Registro General de Cooperativas. Este alcance punitivo de la normativa ecuatoriana es novedoso en el ámbito latinoamericano.

11 DL 305/12, Arts. 14 al 30. 
identidad cooperativa, por lo que resultan incompletos; y de otra, la ausencia de indicadores sociales que limita la evaluación del impacto social de la cooperativa.

Estas limitaciones desde el punto de vista jurídico han tenido además marcada incidencia en la práctica cooperativa. El hecho de que el BSC no se establezca por mandato legal ha traído consigo que las CNA, en su mayoría, no lo realicen (Alfonso et al., 2009)12, desconociéndose los beneficios que este reporta. Aún los asociados y los propios directivos de las cooperativas desconocen el significado real de la RSC, el lugar que ocupan dentro de la cooperativa, en la que no son considerados como un recurso, sino como una potencialidad en movimiento, restándole igualmente importancia a la necesidad de un ejercicio de transparencia que permita la autoevaluación de la cooperativa, la información y rendición de cuentas a los miembros y a la comunidad sobre el impacto social de las actividades que en este orden se ejecutan. Tal es así, que en la mayoría de las CNA no se efectúa un diagnóstico inicial de la situación social, ni tampoco se seleccionan las necesidades sociales y expectativas a enfrentar por la cooperativa, según significado social, grado de compromiso y disponibilidad de recursos propios y otros que se obtengan por gestión. No son tampoco planificadas acciones sociales concretas, ni las funciones y tareas que corresponden al personal directamente vinculado con el proceso.

Sin el BSC se dificulta también que las autoridades controladoras y evaluadores, presenten resultados comparables en relación al grado de cumplimiento de los principios cooperativos, así como la adopción, en el orden administrativo, de las medidas que correspondan aplicar a las cooperativas que no cumplan con el reporte del BSC o que tengan un desempeño social no satisfactorio.

Llegado a este punto, estamos de acuerdo en que encauzar legalmente y llevar a vías de hecho el BSC será un paso más para dotar de transparencia la gestión cooperativa de las CNA en nuestro país. Ello, necesariamente, tal y como ha aseverado Soto, deberá desarrollarse a partir de un conjunto de presupuestos teóricos-jurídicos derivados de la propia esencia y naturaleza cooperativas, y que deberán ser considerados en la futura Ley General de Cooperativas en Cuba (Soto, 2017).

Así, el BSC regulado en una futura normativa con carácter de Ley y aplicable a todas las cooperativas, deberá ser concebido como una herramienta de gestión

12 En los últimos años se han incrementado los estudios en el país sobre los diferentes modelos de balance social aplicados a las cooperativas, en La Habana, Pinar del Río y Villa Clara. Aunque se han centrado en el sector agropecuario, arrojan elementos importantes a analizar en la construcción de un modelo de BSC integral aplicable a todas las cooperativas. El primero de ellos fue desarrollado por el Centro de Estudios de Desarrollo Cooperativo y Comunitario (CEDECOM) de la Universidad de Pinar del Río. Al frente del equipo de trabajo se encontraba el Dr. Juan Luis Alfonso Alemán, los que presentaron un modelo de gestión social en la Cooperativa de Créditos y Servicios «Camilo Cienfuegos». El modelo fue extendido posteriormente, en el año 2009, a la Cooperativa de Producción Agropecuaria «14 de junio», en la propia provincia de Pinar del Río. Tuvo como principal objetivo diseñar un Sistema de Contabilidad del Balance Social para las Empresas Cooperativas que permita registrar, medir y evaluar su desempeño o acción social. Para el estudio del modelo fueron analizados los indicadores sociales más representativos: Solvencia Social, Rentabilidad social y Liquidez Social, en correspondencia a las técnicas utilizadas en la dinámica económica y financiera, pero ajustadas a la especificidad de la acción social. Dada la complejidad del modelo, este fue perfeccionado con posterioridad, en función de lograr la motivación de las entidades cooperativas en su aplicación efectiva. La implementación del modelo perfeccionado de gestión social se realizó durante el período 2011 a primer semestre de 2012 y abarcó un total de 6 formas organizacionales cooperativas (también del sector agropecuario) en las que se logró demostrar la validez y utilidad de dicho proceso de perfeccionamiento. 
empresarial, contenido en un informe de alcance público y cuya información social contenida tendrá carácter obligatorio, que permitirá la evaluación interna y externa del cumplimiento de la Responsabilidad Social de la cooperativa en un período determinado, mediante el uso de indicadores sociales. En el contexto cubano coadyuvaría además a llevar a cabo la comparación por las entidades verificadoras y auditores del grado de cumplimiento de los principios cooperativos, estimulando las mejores cooperativas y desenmascarando las falsas que puedan crearse (carácter externo) y a las propias cooperativas rediseñar sus estrategias, establecer comparaciones con etapas precedentes, en fin, autoevaluarse (carácter interno). El espacio temporal coincidiría con el espacio del balance financiero, ano fiscal, y respondería esta herramienta a estrategias previamente diseñadas y acordadas por los propios socios.

En fin, el reconocimiento y apoyo del Estado a la acción social directa de las cooperativas deberá basarse en un redimensionamiento de sus relaciones con el cooperativismo, a partir de la adopción de instrumentos legales que despojen a la gestión social de su carácter voluntario u opcional, coadyuvando así a un mejor gobierno, transparencia y Responsabilidad Social.

Si pretendemos contar con un buen gobierno cooperativo, este necesariamente habrá de estar dirigido tanto hacia la participación democrática de los socios en las actividades de la cooperativa como hacia el correcto funcionamiento de los órganos de gobierno y control, así como hacia una gestión sostenible que satisfaga las expectativas de todos sus grupos de interés. Desde esta perspectiva, el buen gobierno de la cooperativa exige que se identifiquen los grupos de interés prioritarios, en términos de poder de control, legitimidad moral o contractual y urgencia de sus demandas; que se incorporen las expectativas de los grupos en las políticas, y que se evalúe si se da respuesta a sus demandas, con el objeto de lograr un alineamiento de intereses entre los grupos y la propia sociedad cooperativa (Pedrosa y García, 2011) evitando las asimetrías de información entre los partícipes.

Para ello, uno de los requerimientos de la RSC y del buen gobierno es la transparencia, es decir, la comunicación de los compromisos adquiridos con los grupos de interés, de los impactos económicos, sociales y medioambientales de sus actuaciones; y de la estructura organizativa y operativa de la entidad (Horrach y Socias, 2011). La transparencia y la rendición de cuentas son prácticas esenciales del buen gobierno, entendiendo por estas no sólo las que afectan directamente al funcionamiento del órgano de gobierno, sino todas aquellas que contribuyen a fortalecer el capital institucional de la organización, clave para su sostenibilidad.

La transparencia es una exigencia de la RSC, a través de ella las cooperativas pueden alcanzar legitimidad; pero también es un fin de las organizaciones en sí mismas, porque genera confianza e incide en su reputación, además de acrecentar la fidelización de los socios (Morales, 2005). La transparencia supone así un ejercicio de responsabilidad, pero al mismo tiempo es un medio para que los compromisos asumidos por la cooperativa sean conocidos, aprobados y controlados por sus grupos de interés. 


\section{Conclusiones}

Una vez culminado el desarrollo de este trabajo, sobre la base del objetivo propuesto, se arriban a las siguientes conclusiones:

$1^{\text {a }}$ : En todo tipo de empresas, pero muy en especial en las cooperativas, para lograr la implicación de los socios, la transparencia es un elemento central. Asumirla implica ante todo rendir cuentas de la gestión de forma responsable, lo que demanda necesariamente actitud y disponibilidad de informar, así como la garantía de acceso, apertura y visibilidad de la información, en cuya obtención y distribución deberán participar todos los sujetos implicados.

$2^{\text {a }}$ : La RSC se vislumbra como principio que hace valer la identidad cooperativa, que desecha la concepción de la cooperativa como una unidad técnica, económica y financiera exclusivamente, elevando a rango esencial la misión social que en su actuar deben cumplir, para lo cual se requiere contar con un modelo de gestión transparente en el que se comprometan a contribuir con el desarrollo y mejoramiento de la calidad de vida de los asociados, de sus familias y la comunidad, a partir de procesos económicos eficientes.

$3^{\text {a: }}$ El BSC constituye hoy un mecanismo necesario si pretendemos dotar de transparencia la gestión cooperativa, toda vez que, por su propia naturaleza, permite evaluar, de forma clara y objetiva, la RSC, al proporcionar información acerca de todas las acciones socialmente responsables implementadas en beneficio no solo de los socios, sino también para mejorar el entorno social en el cual se desarrollan.

$4^{\mathrm{a}}$ : La RSC de las CNA en Cuba ha estado marcada por limitaciones tanto en el orden jurídico como práctico. Su ordenación normativa precisa del establecimiento de un marco regulatorio e institucional propicio, que implica la emisión de una Ley General de Cooperativas que ordene y sistematice los principios generales del cooperativismo en Cuba; partiendo del estímulo al desarrollo de acciones socialmente responsables y de una herramienta de carácter obligatorio de medición de cumplimiento e impacto. Será este un paso más en aras de lograr que en la práctica la cooperativa sea instrumentada conforme a su identidad, articulándose el ejercicio de su autonomía, con el cumplimiento de su responsabilidad respecto a la satisfacción de las necesidades sociales y económicas de las personas.

\section{Referencias bibliográficas}

\section{TEXTOS}

Alfonso Alemán, A.L. (2008) Modelo de gestión de la responsabilidad social cooperativa directa. Estudio de caso: cooperativa de producción agropecuaria Camilo Cienfuegos, Tesis presentada en opción al grado científico de Doctor en Ciencias Económicas, 
Centro de Estudios de Desarrollo Cooperativo y Comunitario, Facultad de Ciencias Económicas, Universidad de Pinar del Río, Pinar del Río.

Alfonso Alemán, J. L., Rivera Rodríguez, C. A. y Labrador Machín, O. (2008) Responsabilidad y balance social en las empresas cooperativas, Revista de Ciencias Sociales, № 1, Vol. 14, pp. 09-19.

Alfonso Alemán, J. L., Rivera Rodríguez, C. A. y Labrador Machín, O. (2013) Perfeccionamiento del Modelo de Gestión Social en las empresas cooperativas de la provincia de Pinar del Río. Resultados e Impactos, Revista Avances, № 1, Vol. 15, pp. 40-53.

Alonso, M. (2009) La transparencia de las empresas en internet para la confianza de los accionistas e inversoras: Un análisis empírico. Cuadernos de Administración, $\mathrm{N}^{\mathrm{o}} 38$, Vol. 22, Pontificia Universidad Javeriana, Colombia.

Andrade Castro, J. A. y Yedra Hernández, Y. (2007) Sistemas trasparentes para gobiernos electrónicos eficientes. (U. d. Zulia, Ed.) Enl@ce: Revista Venezolana de Información, tecnología y conocimiento, 4 (2).

Arcas Lario, N. y Briones Peñalver, A. J. (2009) Responsabilidad Social Empresarial de las Organizaciones de Economía Social. Valoración de la misma en las empresas de la Región de Murcia, CIRIEC-España, Revista de Economía Pública, Social y Cooperativa, $\mathrm{N}^{\circ}$ 65, pp. 143-165.

Arellano Gault, D. y Lepore, W. (2009) Reformas de transparencia: hacer endógena la transparencia organizacional. El caso de México. (E. C. México, Ed.) Foro Internacional, XLIX (2).

Arnáez Arce, V.M. (2014) Educación, formación e información. El compromiso cooperativo con la juventud, en Arnáez Arce, V.M. (coordinadora): Difusión de los valores y principios cooperativos entre la juventud, Ed. Dykinson, S.L., Madrid.

Arredondo Trapero, F. G., De La Garza García, J. y Vázquez Parra, J. C. (2014) Transparencia en las organizaciones, una aproximación desde la perspectiva de los colaboradores. Estudios Gerenciales; (30).

Bastidas Delgado, O. (2004) La especificidad cooperativa. Universidad Central de Venezuela, Caracas.

Ballvé, A. M. y Debeljuh, P. (2006) Misión y valores. La empresa en busca de su sentido. (1era. ed.). Buenos Aires: Gestión 2000.

Baraibar Diez, E. y Luna Sotorrío, L. (2012) Transparencia social e hipótesis del impacto social. Análisis en el IBEX35. (P. U. S.A., Ed.) Universia Business Review (36).

Bravo, R., Matute, J. y PINA, J. M. (2011) Efectos de la imagen corporativa en el comportamiento del consumidor. Un estudio aplicado a la banca comercial. (U. N. Colombia, Ed.) Innovar. Revista de Ciencias Administrativas y Sociales, № 21, Vol. 40.

Briones Peñalver, A.J. (2010) Responsabilidad social de las empresas de Economía Social: estudio de las dimensiones que influyen en los resultados. En: XX Jornadas HispanoLusas de Gestión Científica, Évora (Portugal).

Capron, M. (2001) Intereses, límites y perspectivas de un nuevo instrumento de autoevaluación de las organizaciones: el balance cooperativo. CIRIEC-España, Revista de Economía Pública, Social y Cooperativa, № 39, pp. 79-92.

Castro, M. (2006) Las empresas de economía social y la responsabilidad social corporativa, Papeles de Economía Española, № 108, pp. 92-105.

Carrasco, I. (2005) La Ética como Eficiencia: la Responsabilidad Social en las Cooperativas de Crédito Españolas, CIRIEC-España, Revista de Economía Pública, Social y Cooperativa, $\mathrm{N}^{\mathrm{o}}$ 53, pp. 351-367. 
Carrasco, I. (2007) Corporate Social Responsibility, Values and Cooperation. International Journal in Advanced Economic Research, $\mathrm{N}^{\mathrm{o}}$ 4, Vol. 13, pp. 454-460.

Carreras, Ll. y Bastida, R., (2015) Estudio sobre la rendición de cuentas en materia de responsabilidad social: el balance social, CIRIEC-España, Revista de Economía Pública, Social y Cooperativa, No 84, pp. 251-277.

Castilla Polo, F. y D. Gallardo Vázquez, (2014) La revelación social en sociedades cooperativas: una visión comparativa de las herramientas más utilizadas en la actualidad, REVESCO. Revista de Estudios Cooperativos, Primer Cuatrimestre, $\mathrm{N}^{\mathrm{o}} 114$, pp. 7-34. DOI: 10.5209/rev_REVE.2014.v114.44291.

Cracogna, D. (1980) El Balance Social de la Empresa, Revista Administración de Empresa, $\mathrm{N}^{\mathrm{o}} 124$, pp. 36-52.

Cracogna, D. (1995) Los principios cooperativos en el Proyecto de Ley Marco para las Cooperativas de América Latina, en Boletín de la Asociación Internacional de Derecho Cooperativo No 23 y 24, Facultad de Derecho, Universidad de Deusto, Bilbao, 1995.

Coterrel, R. (2000) Transparency, mass media, ideology and community. Cultural Values.

Chávez, C. y Patraca, V. (2011). El comercio justo y la responsabilidad social empresarial. Reflexiones desde los sistemas de certificación autónoma. Argumentos, № 65, Vol. 24, Universidad Autónoma Metropolitana - Xochimilco, Distrito Federal, México.

Duque Domínguez, J.F. (1998) Principios cooperativos y experiencia cooperativa, en Congreso de Cooperativismo, Universidad de Deusto, Bilbao.

Góngora, H., Rodríguez, P. y Zumárraga E. (2017) Importancia del Balance Social en las Cooperativas en Ecuador. CienciAmérica, Vol. 6 (2), ISSN 1390-9592.

Gower, K.K (2006) Truth and transparency. In K. Fitzpatricj and C. Bronstein (Eds.), Ethics in public relations, Thousand Oaks, CA: Sage.

Heise, J.A. (1985) Toward closing the confidence gap: An alternative approach to communication between public and government. (196-217). Public Affairs Quaterly, $\mathrm{N}^{\mathrm{o}}$ 9, pp. 196-217.

Hernández Aguilar, O. y Rodríguez Musa, O. (2015) La enseñanza del Derecho de Cooperativas dentro del modelo de la Educación Superior en Cuba. La experiencia en la Universidad de Pinar del Río, en Arnáez, V.M.: Difusión de los valores y Principios Cooperativos entre la Juventud, Ed. Dykinson S.L., Madrid.

Hernández Santoyo, A., Pérez León, V.E. y Alfonso Alemán, J.L. (2009) La Gestión y el Balance Social en la Empresa Cooperativa Cubana. Caso de Estudio: CPA 14 de junio, Revista Contabilidad y Auditoría, No 29, pp. 63-77.

Horrach, P. y Socias, A. (2011) La actitud de las empresas de economía solidaria frente a la divulgación de información sobre sostenibilidad desde el prisma de la teoría de los Stakeholders o grupos de interés. Revista de Contabilidad-Spanish Accounting Review Vol. 14 - No Extraordinario, pp. 267-297.

Lamas Nolasco, A. (2009) Cooperativas: negocios socialmente responsables. El Economista, 11 de junio de 2009.

Marcuello, C. y Bellostas, A., (2007) Transparencia y rendición de cuentas en las empresas de inserción. CIRIEC-España. Revista de Economía Pública, Social y Cooperativa, N ${ }^{\circ}$ 59, Centro Internacional de Investigación e Información sobre la Economía Pública, Social y Cooperativa. Valencia, España.

Medina, J., Lavín, J., Mora, A., y De La Garza, I. (2011) Influence of information technology management on the organizational performance of the small and mediumsized enterprises. (U. N. Colombia, Ed.) Innovar. Revista de Ciencias Administrativas y Sociales, $\mathrm{N}^{\mathrm{o}} 21$ (42). 
Mena Lazo, C., Llánez Guerra, O., Jiménez Guethón, R. y Arjona Vázquez, O. (2014) Modelo de Balance Social Cooperativo ICA-FLACSO-PC. Compendio para la implantación. La Habana, Cuba.

Morales Gutiérrez, A. C. (2005) Círculos Virtuosos en la Cooperación, Sociedad Cooperativa, $\mathrm{N}^{\mathrm{o}} 15$, pp. 30-34.

Mozas Moral, A. y Puentes Poyatos, R. (2010) La Responsabilidad Social Corporativa y su paralelismo con las Sociedades Cooperativas, REVESCO. Revista de Estudios Cooperativos, Tercer Cuatrimestre, № 103, pp. 75-100.

Mozas Moral, A., Puentes Poyatos, R. y Bernal Jurado, R. (2010) La Ecorporate Social Responsibility en las sociedades Cooperativas Agrarias Andaluzas, CIRIEC-España, Revista de Economía Pública, Social y Cooperativa, No 67, pp. 187-212.

Mugarra Elorriaga, A. (1999) Proyecto de Balance de Identidad Cooperativa, en Anuario de Estudios Cooperativos, (Universidad de Deusto, Bilbao,1999), pp. 303-390.

Mugarra Elorriaga, A. (2001) Responsabilidad y balance social hoy en día: un reto para las cooperativas. CIRIEC-España, Revista Jurídica de Economía Social y Cooperativa, N ${ }^{\circ}$ 39 , pp.25-50.

Mugarra Elorriaga, A. (2005) Memoria de sostenibilidad. Una propuesta adaptada para las cooperativas de enseñanza del País Vasco, CIRIEC-España, Revista de Economía Pública, Social y Cooperativa, No 53, pp. 333-349.

Mugarra Elorriaga, A. (2009) Modelos de Balance Social: Criterios clasificatorios, Instituto de Estudios Cooperativos Coleccion de casos, pp. 1-28.

Muñoz Pasadas, R.; Tirado Valencia, P. y Ruiz Lozano, M. (2010) Una propuesta de herramientas para la gestión de la transparencia en las entidades no lucrativas, Revista de Fomento Social, № 260, pp. 695-726.

Murayama, C. (2007) Obligaciones de transparencia en las universidades. (I. d. Educación, Ed.) CPU-e, Revista de Investigación Educativa (4).

Ochoa Henríquez, H. y Montes De Oca, Y. (2004) Rendición de cuentas en la gestión pública: Reflexiones teóricas. (U. d. Zulia, Ed.) Revista Venezolana de Gerencia, № 9 (27).

Palomo Zurdo, R. J. y Valor Martínez, C. (2004) El “activismo" de los socios como catalizador de la Responsabilidad Social de la Empresa: aplicación a Organizaciones de Participación, CIRIEC-España, Revista de Economía Pública, Social y Cooperativa, № 50, pp. 167-190.

Pedrosa Ortega, C. y García Martí, E. (2011) El Gobierno en la Sociedad Cooperativa como Base de la Cohesión Social: el caso de una cooperativa agraria, REVESCO. Revista de Estudios Cooperativos, Tercer Cuatrimestre, No 106, pp. 7-32. DOI: 10.5209/rev_REVE.2011.v106.37372.

Pérez Sanz, F. J. y Gargallo Castel, A. (2005) Gestión, Desarrollo y Aplicación de la Responsabilidad Social en Entidades de Economía Social: el caso de las cooperativas, CIRIEC-España, Revista de Economía Pública, Social y Cooperativa, No 53, pp. 305332.

Pzá Tomás, O. (1997) La transparencia de informacion como base del contrato federal: una propuesta para México. (F. L. Sociales, Ed.) Perfiles Latinoamericanos, № 10.

Rawlins, B. (2009) Give the Emperor a Mirror: Toward Developing a Stakeholder Measurement of Organizational Transparency. Journal of Public Relations Research, $\mathrm{N}^{\mathrm{o}} 21$.

Rodríguez Musa, O. (2017) La constitucionalización de la cooperativa. Una propuesta para su redimensionamiento en Cuba, Coletânea IBECOOP, $\mathrm{N}^{\circ}$ 1, Ed. Vincere Asociados, Brasilia-DF. 
Rodríguez, M., (2013) Balance social. Abc de una herramienta clave para la rendición de cuentas: Editorial Errepar, $1^{a}$ edición.

Ressel A.B. y Coppini, V. (2012) El Balance Social y su importancia como instrumento de medición en las organizaciones de la economía social, particularmente en las cooperativas, VII Congreso Internacional Rulescoop Economía social: identidad, desafíos y estrategias Valencia-Castellón (España), 5-7 de Septiembre de 2012.

San Bartolome (2010) Balance social cooperativo: una responsabilidad intrínseca de la empresa cooperativa. Foro Balance Social Cooperativo y Gobernabilidad. XVII Conferencia Regional de ACI AMERICAS. Conferencia pronunciada en Buenos Aires, Argentina el 22 de noviembre de 2010.

San Bartolome, J. C., y González, L. (2008) Balance Social Cooperativo: Una construcción en construcción, Ediciones Red Gráfica, Buenos Aires.

Sandoval, E. (2006) Visibilidad, privacidad y transparencias: los límites de la comunicación. (I. T. Monterrey, Ed.) Global Media Journal , № 3, Vol. 6.

Server Izquierdo, R. y Capó Vicedo, J. (2009) La Responsabilidad Social Empresarial en un contexto de crisis. Repercusión en las Sociedades Cooperativas, CIRIEC-España, Revista de Economía Pública, Social y Cooperativa, № 65, pp. 7-31.

Server, R.J. y Capó Vicedo, J. (2011) The interrelationship between the demands of Corporate Social Responsibility and cooperative principles and values. CIRIEC ESPAÑA, Revista de Economía Pública, Social y Cooperativa.

Server Izquierdo, R. y Villalonga, I. (2005) La Responsabilidad Social Corporativa (RSC) y su gestión integrada. CIRIEC-España, Revista de Economía Pública, Social y Cooperativa, $\mathrm{N}^{\circ}$ 53, pp. 137-161.

Soto Alemán, L. (2017) La Responsabilidad Social Empresarial en Cuba: Una visión desde el conocimiento jurídico en pos del desarrollo local, Revista Jurídica DEREITO, Universidad Santiago de Compostela, España, No 1, Vol. 25, pp. 101-115.

Tous Zamora, D. y Ciruela Lorenzo, A.M. (2005) Responsabilidad social y cultura en las sociedades cooperativas agrarias. Modelo general de Balance Social. CIRIEC España, Revista de Economía Pública, Social y Cooperativa, No 53, pp. 209-240.

Uvalle, R. (2007) Gobernabilidad, transparencia y reconstrucción del Estado. (U. A. México, Ed.) Convergencia. Revista de Ciencias Sociales, № 14.

Villanueva, E. (2011) Aproximaciones conceptuales a la idea de transparencia. Ponencias. IFAI.

Vuotto, M. y Verbeke, G. (2015) Las cooperativas no agropecuarias en Cuba en el contexto de transformación de la Cuba de hoy. Desafíos actuales». Conferencia XII Congreso Nacional de estudios del trabajo. Grupo Temático N. ${ }^{\circ}$ 11: Trabajo y autogestión en las organizaciones de la economía Social. Conferencia pronunciada en Buenos Aires, Argentina en agosto de 2015.

\section{LEGISLACIÓN}

Constitución de la República de Cuba de 1976, reformada en 1992, Gaceta Oficial Extraordinaria $\mathrm{N}^{\mathrm{o}} 7$ de $1^{\circ}$ de agosto de 1992.

Constitución de la República de la República de Cuba, Gaceta Oficial Extraordinaria No. 3 de 31 de enero de 2003.

Ley $\mathrm{N}^{\mathrm{o}}$ 95, De las Cooperativas de Producción Agropecuaria y de Créditos y Servicios, de fecha 2 de noviembre de 2002.Gaceta Oficial $N^{\circ} 72$ Ordinaria de 29 de noviembre de 2002. 
Ley N 107 de fecha 1ro de agosto de 2009, De la Contraloría General de la República. Gaceta Oficial de la República de Cuba No 29 Extraordinaria de14 de agosto de 2009.

Ley No. 113 de fecha 23 de julio de 2012, Del sistema Tributario. Gaceta Oficial No 53 Extraordinaria de 21 de noviembre de 2012.

Decreto-Ley No 305/2012 "De las cooperativas no agropecuarias", Gaceta Oficial No 053 Extraordinaria de 11 de diciembre de 2012.

Decreto $\mathrm{N}^{\mathrm{o}} 309$ Reglamento de las Cooperativas no Agropecuarias de primer grado, de fecha 28 de noviembre de 2012. Gaceta Oficial No 53 Extraordinaria de 11 de diciembre de 2012.

Resolución No 427/12 de fecha 4 de diciembre de 2012 de la Ministra de Finanzas y Precios, Norma específica de Contabilidad $N^{\circ} 7$ para cooperativas no agropecuarias. Gaceta Oficial de la República de Cuba No. 53 Extraordinaria de 11 de diciembre de 2012.

\section{DOCUMENTOS}

Alianza Cooperativa Internacional, Plan para una década cooperativa, Visión 2020, 2013, [on line], disponible en: https://www.aciamericas.coop/-Decada-cooperativa- Acceso el 16 de marzo de 2017.

Ley Marco para las cooperativas de América Latina/ Alianza Cooperativa Internacional para las Américas. - 1a ed.- San José, Costa Rica: Alianza Cooperativa Internacional para las Américas, 2009.

Lineamientos de la Política Económica y Social del Partido y la Revolución, aprobado en el VI Congreso del Partido el 18 de abril de 2011 y en el Séptimo Período Ordinario de Sesiones de la VII Legislatura de la Asamblea Nacional del Poder Popular el $1^{\circ}$ de agosto de 2016.

Partido Comunista de Cuba, VII Congreso: Actualización de los Lineamientos de la Política Económica y Social del Partido y la Revolución para el período 2016-2021, abril de 2016, Disponible en: http://www.granma.cu/file/pdf/gaceta/Lineamientos\%2020162021\%20Versi\%C3\%B3n\%20Final.pdf/. Acceso el 20 de octubre de 2017.

Resolución No. 4109 de fecha 30 de enero de 2009 del Presidente del Instituto Nacional de Cooperativismo de Paraguay, «Balance social cooperativo». Disponible en: http://www.incoop.gov.py/v2/?p=374. Acceso el 15 de enero de 2018.

UNIRCOOP (2007). Informe Final del Comité Académico "Instrumentos de medición de la responsabilidad social en las cooperativas". 